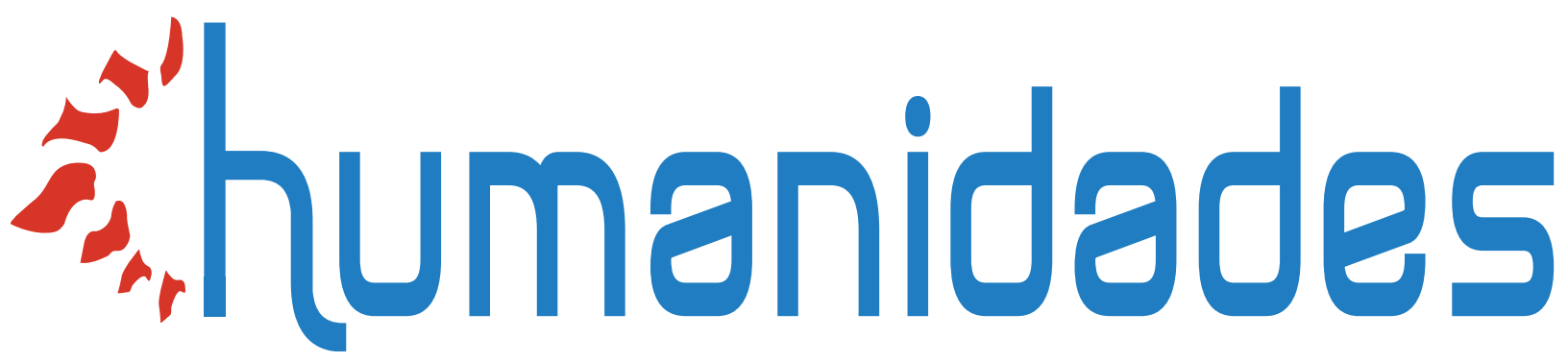

\title{
La geopolítica cinematográfica de los zombis: notas para el debate
}

\author{
Xavier Brito Alvarado \\ Saudia Levoyer Salas
}

DOl: https://doi.org/I0.155 I7/h.v10i2.4I767 https://revistas.ucr.ac.cr/index.php/humanidades/index

(c) (1) ()

Universidad de Costa Rica 


\section{"humanidades}

Revista Humanidades

ISSN: 2215-3934

humanidades@ucr.ac.cr

Universidad de Costa Rica

Costa Rica

\section{La geopolítica cinematográfica de los zombis: notas para el debate}

Brito Alvarado, Mag. Xavier; Levoyer Salas, Dra. Saudia

La geopolítica cinematográfica de los zombis: notas para el debate

Revista Humanidades, vol. 10, núm. 2, 2020

Universidad de Costa Rica, Costa Rica

Disponible en: http://www.redalyc.org/articulo. oa?id=498062469011

DOI: https://doi.org/10.15517/h.v10i2.41767

Esta obra está bajo una Licencia Creative Commons Atribución-NoComercial-SinDerivar 3.0 Internacional 
Desde las ciencias sociales, la filosofía y la educación

\section{La geopolítica cinematográfica de los zombis: notas para el debate}

Cinematic Geopolitics of Zombies: Notes for Debate

Mag. Xavier Brito Alvarado

Universidad Técnica de Ambato, Ecuador

DOI: https://doi.org/10.15517/h.v10i2.41767

Redalyc: http://www.redalyc.org/articulo.oa?

lx.brito@uta.edu.ec

$\mathrm{id}=498062469011$

iD http://orcid.org/0000-0001-8593-3691

Dra. Saudia Levoyer Salas

Universidad Andina Simón Bolivar, Ecuador

saudia.levoyer@uasb.edu.ec

(iD http://orcid.org/0000-0003-3708-751X

Recepción: 12 Febrero 2020

Aprobación: 20 Abril 2020

\section{RESUMEN:}

El zombi ha dejado de ser la estrella de películas de bajo presupuesto y se ha convertido en un concepto científico (biológico, social, económico y tecnológico), en una metáfora para la reflexión de las diversas problemáticas sociales, es un ente que ha pasado de humano a lo poshumano, hasta llegar a ser un antisujeto. El zombi causa temor en dos direcciones: la primera, en ser devorado por este y la segunda, en convertirse en uno. Su posicionamiento ontológico lo ubica entre el sujeto y el objeto, rompiendo los modelos duales, no importa el género, la condición socioeconómica, ni la geografía, por ello es la metáfora ideal para el análisis social contemporáneo, donde las miradas marxistas, poscoloniales, de género, posestructuralistas, posmodernas y las teorías poshumanistas entran en diálogo. Desde un abordaje teórico, proveniente de la antropología, la sociología y el cine, este ensayo reflexiona al zombi por fuera de las clásicas miradas reduccionistas que lo han ubicado como un producto cultural marginal, destinado a satisfacer momentos lúdicos, contrario a esta postura, lo que se intenta, más bien, es dar una visión crítica del zombi y su injerencia social contemporánea.

Palabras clave: Cine, Gobernabilidad, Geopolítica.

\section{ABstraCT:}

The zombie has ceased to be the start of low-budget films and has become a scientific concept (biological, social, economic and techonological), a metaphor for the reflection of the varius social problems, in an entity that has gone from human to posthuman, until becoming an antisubject. The zombie causes fear in two directions: the first, to be devoured by it and, the second, to become one. Its ontological position places it between the subject and the object, breaking the dual models, regardless of gender, socioeconomic statu or geography, so it is the ideal metaphor for contemporany social analysis, where marxist, post cololinal and gender, post structuralist, postmodern, posthumanist theories can dialogue. From a theoretical approach, from anthropology, sociology and cinema, this essay ponder on the zombie outside the classical reductionist views, which have placed it as a marginal cultural product, intended to satisfy playful momento, contrary to this position, what is intended, rather, is to give a critical view of the zombie and its contemporary social interference.

KEYwORDS: Cinema, Governance, Geopolitics.

\section{Pensar AL ZOMBI, A MANERA DE INTRODUCCión}

El zombi, para fines de este trabajo, se lo usa como metáfora para describir a los sujetos cosificados que se encuentran en cualquier sistema económico. Se los puede identificar por su capacidad de acoplamiento a las circunstancias en las que se encuentra, sean estas políticas, económicas o sociales (biopolítica), así como por su capacidad consumidora. Este fenómeno, dadas las circunstancias de cómo se multiplican estos seres, puede 
tener un alcance a nivel planetario, así como el de los sistemas económicos con sus respectivas relaciones y conflictos.

La llegada del zombi a las pantallas de cine y televisión no es un fenómeno mediático nuevo, la primera película oficial de zombis fue White Zombie de Victor Halperin (1932), la cual permaneció dentro de la categoría "B" del cine por muchos años. No fue hasta la década de los sesentas cuando el cine zombi explotó como una industria fílmica a gran escala. El gran salto se dio gracias al director George A. Romero quien ubicó a los zombis más allá de los relatos fantasiosos, centrándose en que estos seres funcionan como una crítica social.

Los zombis en el cine son representados dentro de los aspectos más reprobables de la humanidad: lo irracional, la autodestrucción y lo despiadado. "Desde donde entender el entorno mediatizado que nos rodea: desequilibrios financieros, pasiones reducidas al pastiche de su expresión hiperreal, modelos de pensamiento afianzados por el poder y consolidados en la puesta en práctica de la maquinaria capitalista" (Fernández, 2001, p. 11).

Para Stephanie Boluk y Wylie Lenz (2011), el cine zombi puede dividirse en tres etapas. La primera, centrada en la visión clásica del zombi, un muerto que ha sido resucitado por medio de un ritual vudú haitiano, cuyo período abarca desde 1939 hasta 1969. En estas historias prevalece el imaginario colonialista blanco contra lo afrocaribeño, se alude a una época marcada por una dialéctica entre el amo y el esclavo; el primero, asumido como el hechicero, el terrateniente o el científico y, el segundo, como el sujeto zombificado. De esta forma "existe una clara dependencia del monstruo con respecto a su creador [...] que remite a los temores coloniales propios de una población permanentemente en represión como es la haitiana, proceso que se denomina un imperialismo psíquico” (Sánchez, 2013, p. 15).

La segunda etapa llamada George Romero, padre del zombi moderno, que ha proporcionado una línea crítica a este personaje. Para Boluk y Lenz (2011), esta etapa posee cuatro innovaciones: los zombis ya no son un producto de ritual vudú, demográficamente superan a los humanos, el canibalismo es uno de los hilos conductores de las narraciones y la idea del contagio viral masivo. Sin embargo, Sánchez Trigos (2013) aumenta una característica: la disolución de la dialéctica del amo y el esclavo que, no obstante, aún se encuentra presente en ciertas películas como la saga de las producciones Resident Evil y Fido. En esta etapa el zombi es un monstruo a escala global, por tanto, es un ser masificado y peligroso para el orden social.

En la última etapa, el zombi se ha convertido en una amenaza mundial, es un ser infectado, pero a diferencia de sus antecesores ya no es torpe, ataca en hordas, es un producto de la manipulación genética o de los experimentos bioquímicos, "formalmente, este zombi ya no deambula con aspecto lánguido por las ciudades vacías en busca de alimento, sino que se ha trasmutado a un ser furioso y salvaje” (Sánchez, 2013, p. 17).

David Chalmers (1999) ha descrito al cine sobre zombis desde una triple perspectiva analítica: uno, el cadáver reanimado destinado a comer a los seres humanos; dos, una mirada haitiana de la magia y el ritual vudú como hacedoras del zombi; tres, la perspectiva de un ser que ha perdido la conciencia debido a ciertas circunstancias como un ataque viral. Rubén Sánchez (2013), cita a Kevin Boon, quien propone una división del zombi para así evitar un reduccionismo dentro del cine: en relación con el cine, el zombi representa un complejo producto cultural, sobre el que recae toda una dramaturgia que mezcla diversos elementos como, por ejemplo, el discurso ideológico del misticismo de África que es conquistada y colonizada por Occidente. De un ser esclavizado ha pasado a constituirse en dominador del planeta. Estos cambios no solo son estéticos visuales, sino que reconfiguran al zombi "como un monstruo con rasgos únicos pero cambiantes, es un ser heterogéneo, un concepto en constante evolución que varía su forma y su significado en función del contexto social en el que se desarrolla" (Añón, 2018, p. 296).

Kyle Bishop (2010) describe que las narratologías de las películas zombis se ubican dentro de una serie de escenarios apocalípticos que poseen una serie de características que colocan a este ser como una metáfora social del fin de la civilización humana, así representan el desplome de las estructuras sociales, el miedo hacia 
el otro, la paranoia a los ataques terroristas con agentes biológicos o la infección por virus que no pueden ser controlados para las fuerzas del orden.

Estos rasgos permiten que una trama básica se repita, con las lógicas variaciones, en el subgénero zombi: un grupo de supervivientes busca refugio en un entorno seguro para enfrentarse a una amenaza que proviene tanto de los zombis como de otro grupo de hombres. Este instinto de supervivencia implica un salto dramático (Verevis, 2010, p. 17).

El cine zombi muestra que las sociedades se han convertido en anómalas, no hay ley ni orden; el desplome civilizatorio llega con el ataque zombi que no solo son unos muertos que resucitan y deambulan con furia atacando a los vivos, sino que muestra el lado más animal que tenemos los humanos, el canibalismo.

La figura del zombi se ubica entre lo grotesco y lo sublime, un ser que no vive, pero tampoco muere, de ahí que su imagen sea algo extraordinario, perpetuable en la imaginación de nosotros. Desde el campo filosófico desafía cualquier postulado ontológico humano, un cuerpo vacío, un cuerpo sin órganos para utilizar el término utilizado por Gilles Deleuze y Slavoj Zizek. La figura del zombi siempre será asumida en lo grotesco, lo putrefacto como algo inhumano. Iratxe Jaio y Klaas van Gorkum (como se citó en Del Olmo, 2012), refieren lo siguiente sobre la estética del zombi:

Los zombis son más bien trágicos anti-héroes, una parodia repulsiva del ciudadano ideal, sin más relación con la experiencia vital que la repetición automática de viejas costumbres de socialización. Y, sin embargo, aunque se empeñen en perseguir a los vivos, uno no puede evitar sentir simpatía por estos inquietantes sonámbulos. En una sociedad en que el significado de la palabra "libertad" es cada vez más escurridizo, no es difícil ver a los muertos vivientes como la reencarnación de aquellos bufones cortesanos, eso sí, en un extraño estado de descomposición y sujetando un espejo que refleja nuestro sentir cívico y humano. Qué poderoso debe ser sentirse uno dentro de su piel. Rechazar toda lógica y objeto de la vida, dejar de correr y empezar a tambalearse, gimiendo y gesticulando con torpeza (2012, pp. 13-14).

Es bajo este paraguas que el zombi posibilita abrir una serie de debates en diferentes áreas sociales, políticas, económicas, estéticas e ideológicas contemporáneas. De ahí que posee un valor epistémico crítico-teórico alternativo a la racionalidad dominante de occidente, como sugiere Moraña (2017), quien además plantea que el zombi es revestido de discursos apropiados para cada situación histórica, como una especie de un simulacro estético e ideológico que une y separa idea y representación del ser humano. El zombi, como dispositivo epistémico, surge a partir de su singularidad y performatividad, pero, ante todo, deja de tener una corporeidad propia, no posee zoé ni bios, convirtiéndose en una vida nuda, por ello opera bajo una identidad abierta que niega la vida y la muerte.

Desde una mirada crítica proveniente de la teoría social contemporánea, el zombi representa una transgresión a la conducta normal de los sujetos, a partir de una descripción de la anatomía política normativa que, en palabras de Rosi Braidotti (2009), desafía la morfología “antropocéntrica generizada y racializada”. En las sociedades cada vez más acorraladas por el poder de las mercancías, el zombi representa la seducción al consumo, no necesita hablar ni manifestar sus cualidades, solo caminar, agitar sus manos, gesticular y devorar mercadería.

La película de George Romero Dawn of the Dead (1978) ya denunció que el peligro de convertirse en zombi no radica en el mordisco, sino en el consumismo irracional de mercaderías que nos conduce a vivir en una sociedad materializada, ya que el consumidor al igual que el zombi satisface sus deseos por medio de cosas que no necesita para vivir. Desde el discurso fílmico esta película es una crítica al consumismo y el mercantilismo, incluso, el lugar de lucha por la sobrevivencia es un centro comercial.

El zombi es un esclavo de sí mismo, es cosa y sujeto a la vez, es un cuerpo sin mente ni alma, solo es masa corporal sin órganos, un vacío anatómico hipertrofiado, una construcción sobre la identidad/otredad que es utilizado para abalizar nuestros miedos y paranoias sobre el fin del mundo. "El tema zombi se inscribe dentro de los parámetros de estas construcciones sobre identidad/otredad, pertenencia/ajenidad, bien/mal, hegemónico/ajenidad, otredad de lo extraño, naturaleza de sentido y valor ideal del bien” (Moraña, 2017, p. 30). 
El zombi es un ser nómada, desterritorializado en todo sentido, es un contra discurso sobre la identidad amenazante, dado que forma un collage de retazos de sujetos que se fusionan en un ente contrario a cualquier discurso ético, religioso y científico. Para Noël Carroll (como se citó en Moraña, 2017) "en efecto, lo monstruoso incorpora una inquietud perturbadora y productiva: afecta el sentido común, desfamiliariza la experiencia cotidiana y desestabiliza los saberes y creencias que rigen el funcionamiento social" (p. 32). Para el zombi la continuidad temporal y espacial no existe, el vacío de su existencia ha borrado toda condición de humanidad, pero, a la vez, se regenera y degenera de forma constante. La figura del zombi parte de una condición neobarroca que, asumiendo la postura de Omar Calabrese (1989), lo presenta como un monstruo proveniente de la oscuridad laberíntica de la vida apocalíptica.

El zombi se sobrepone a la condición de no poseer ni cuerpo ni alma y en su intención de recobrarlas devora a cuanto sujeto encuentra, aumentado así la masa devoradora de la sociedad. Para Jeffrey Jerome Cohen (1996), los zombis son monstruos que no pueden ser pensados desde la esfera de lo biológico, su accionar parte de lo cultural desde donde se expresan diversas cualidades: primero, una expresión de ciertas condiciones coyunturales como los miedos, ansiedades y deseos que nos acosan; segundo, la codificación de los cuerpos excesivos, la figura destruida, arruinada y asaltada de cualquier condición humana; tercero, poner al límite las propias capacidades humanas de tolerancia y respeto a los demás humanos. Para entender a esta figura se requiere decodificarlo y ubicarlo dentro de una "hermenéutica semiótico-ideológica" que pone en debate los diferentes discursos éticos y políticos. Este ser "ocupa el entre-lugar, la fisura que separa y conecta códigos, lógicas y coordenadas espacio-temporales [...] pero sugiere la necesidad de aceptar la imposibilidad de domesticar racionalmente lo real y de extinguir en ese dominio aquello que resiste la normatividad" (Moraña, 2017, p.39).

La función del zombi no es comer a los humanos, es perturbar el statu quo instalado en las sociedades, semióticamente rompe los códigos instaurados, el lenguaje dominante, desestabilizando el orden establecido, pero a la vez visibiliza una precariedad social, la cual es el despojo en el que nos hemos convertido. El zombi representa a los sujetos traumatizados por las actuales condiciones de vida, la falta de capacidad crítica y argumentación por el abuso de las tecnologías de la información, por la farmacología instaurada como forma de vida que "declina un paradigma central en el Occidente contemporáneo: el del individuo golpeado por un drama" (Coulombe, 2012, p. 57).

En este sentido, el zombi saca a la luz la imagen de barbarie reprimida, el mundo en un colapso total, una disolución de la subjetividad, al distorsionar sobre nuestra propia condición de humanos, lo cual implicaría el regreso al estado de la naturaleza.

\section{BiopolíticA zoMBi}

Para Michel Foucault, desde la mitad del siglo XVII la biopolítica se encaminó a un "arte de gobernar" y desde finales del siglo XVIII cambió por "hacer morir y dejar vivir". Con la invasión zombi el discurso biopolítico se centra, por los menos, en cuatro aspectos: uno, lo biológico y la reconfiguración de lo humano como especie dominante en el planeta; dos, lo ecológico-demográfico sobre la capacidad de producir alimentos; tres, lo tecnológico-económico sobre la capacidad de acceder y producir tecnología; cuatro, lo sociopolítico sobre las diversas formas de socializar, una nueva forma de convivencia social alejada de cualquier precepto ético y moral que sostuvo a la civilización antes de una pandemia zombi.

Esta figura representa la excusa para la eliminación de los sujetos que no se han adaptado a las biopolíticas del poder contemporáneo, bajo la forma dual de un código infectado/no infectado que procede a la eliminación de cualquier sospecho de ser un zombi. Al representar sociedades apocalípticas el zombi se convierte en la víctima. No es el problema porque no actúa de forma lógica, solo se mueve por instintos básicos y primarios que en sí representa el rostro que debería asumir cualquier persona que no se somete al 
poder establecido. Este miedo hace que los no infectados busquen en las matanzas de zombis la adaptación al sistema de poder.

Este sistema de poder se encasilla en lo que Ulrich Beck (2002) ha descrito como sociedades del riesgo, sociedades que se encuentran sumergidas en constate temor a la destrucción de la naturaleza, la manipulación genética, entre otros aspectos que ponen al mundo en una amenaza constante. "Los riesgos, de los cuales somos responsables y víctimas, definen la sociedad en la que vivimos. Nos invitan a tomar decisiones sociales y sobre todo racionales, de lo contrario lógico y calculado. Cambian nuestros caminos de aprehender al mundo" (Peris, 2018, p. 123).

Desde otra perspectiva, pero conservando la idea del riesgo, una invasión zombi representaría la creación de sociedades basadas en la vida autárquica, donde nuevas formas biopolíticas serían desplegadas, tendientes a garantizar sociabilidades y enfocadas en determinar quién es apto o no para la supervivencia como especie humana. La guerra contra los zombis se instaura bajo una paradoja de matar a alguien que se encuentra muerto y la supervivencia humana radica en la capacidad de volver a un orden social que se basa en la muerte de los no muertos.

Las historias de zombis narran visiones distópicas, por ello no es descabellado pensar a esta figura como el último enemigo de la humanidad. Una invasión zombi abre el espacio para un debate biopolítico sobre diversas formas de control sanitario: la biopolítica, necropolítica, el estado de excepción basado en la destrucción de la naturaleza, el trabajo tercerizado, el consumismo formando una nueva esclavitud, donde los sujetos son convertidos en objeto del sistema, “[...] tras el vendaval, ya no hay sociedad que nos acoja. Ya no hay Estado que nos proteja. Los Estados postmodernos son hoy estados de excepción continua en los que la alerta y la amenaza son permanentes" (Díaz y Meloni, 2016, p. 67).

El zombi representa la figura ideal para describir diversas claves de la vida contemporánea, estableciendo relaciones con prácticas políticas de control, entre ellas: la salud pública, la demografía, menos humanos más zombis y, por último, lo territorial, el lugar de disputa por el dominio del planeta. Todo esto reconfigura nuevos espacios de sociabilidad, como por ejemplo, una nueva arquitectura urbana que deja de ser una ventaja para los humanos.

Las grandes ciudades han sido abandonadas y las principales autovías que las unen han quedado desiertas o convertidas en cementerios de automóviles. Así las cosas, los pocos individuos que han sobrevivido a la hecatombe parecen condenados a vagar por las zonas más despobladas de la tierra, como sus antepasados nómadas, huyendo de un lado para otro de la constante amenaza zombi (Urraco et al., 2017, p. 9).

Con esta invasión, el discurso biopolítico se centra al menos en cuatro aspectos: 1) lo biológico y la reconfiguración de lo humano, 2) lo ecológico demográfico, es decir, producir alimentos y repoblar al planeta, 3) lo tecnológico-económico, acceso y producción de tecnología y 4) lo sociopolítico, las diversas formas de socializar.

En esta situación y si los humanos no quieren desparecer del planeta deben replantarse los dilemas morales y éticos, dejando de lado cuestiones ideológicas, religiosas o raciales. Una guerra contra los zombis obligaría a los sobrevivientes a confrontar y tomar decisiones difíciles como asesinar a un familiar, dejar morir a los enfermos incurables o reproducirse desde temprana edad. Por ello, el discurso biopolítico forma parte de una declaración en la que se considera "enemigos de la sociedad a todas aquellas razas que no se ajusten a la norma poblacional deseada” (Castro, 2007, p. 157).

En una guerra contra los zombis, la biopolítica se destina a una especie de juzgamiento poblacional de hace vivir y deja morir para aquellos que no se adapten a los nuevos regímenes sociales, incluso para quienes no se han convertido en zombis. Por ello, la guerra se establece entre los humanos:

El zombi por el contrario desconoce toda norma de cortesía, apenas si golpea la puerta, cuando en realidad se topa con ella en su incapacidad de abrirla o hacerse de una herramienta más efectiva que sus pocas hábiles manos para derribarla. Recordemos: el zombi es todo cuerpo (Platzeck, 2016, p. 82). 
Una nueva biopolítica se erige en la sociedad con leyes propias articulando el sentido de obediencia colectiva, ya no es el contrato social el que rige ni el policial ni el político, es el derecho del sobreviviente, dirigido a controlar a la "Gran Bestia", en este caso el zombi. Las nuevas formas del derecho y de la moral se convierten en asuntos importantes, actuando desde el interior de los sujetos, una forma más abierta de control, un nuevo biopoder que forma parte de un conjunto anatomopolítico disciplinar destinado a manipular las conductas de los sujetos para incorporarse en un sistema de vida regulada por la condición de sobrevivir. El zombi escapa a toda lógica de control y cualquier forma de razonamiento y resistencias, no cabe ninguna forma de entendimiento, dando paso a una necropolítica donde "la muerte y sus múltiples figuras de lo no-vivo emergen como su producción más siniestra, pero suponen, paradójicamente, su resto incontrolable, imposible de digerir y de eliminar por completo" (Díaz y Meloni, 2016, p. 35).

\section{EL ESTADO DE EXCEPCIÓN}

Ante una amenaza zombi, cualquier derecho queda suspendido para que las sociedades puedan continuar e inclusive sobrevivir, por medio de la legalidad de la exclusión social de los diferentes. De esta forma, los zombis sirven como excusa para nuevos genocidios y discursos de superioridad racial.

La figura del zombi como objeto de análisis en un estado de excepción parte de la idea de que los conceptos como: el salvaje colonial, los migrantes peligrosos, los terroristas o los discursos de supremacía racial, son insuficientes y esto se debe a que potencialmente todos pueden convertirse en zombis. En un estado donde las poblaciones sin distinción de clases sociales, de género, de condiciones económicas o culturales son potencialmente peligrosas. A esto hay que añadirle que el zombi se acopla muy bien a cualquier régimen político, sea este capitalista, socialista, monárquico, dictatorial, convirtiéndolo en la figura perfecta para generar un estado de excepción, porque su concepto no se agota a diferencia de los mencionados sistemas políticos.

Cualquier estado de excepción conlleva una serie de medidas para erradicar cualquier amenaza y la medida con mayor aceptación es el uso de la fuerza progresiva y total, lo que supone una legitimación de la violencia contra cualquiera. Roberto Esposito (2005) argumenta que en el caso de una amenaza viral se establece un "paradigma inmunitario" donde se vincula los diversos procesos jurídicos, políticos y sanitarios con la finalidad de la construcción de identidades agrupadas bajo el paradigma biopolítico con la intención de salvaguardar a la comunidad.

Ya sea el asediando el cuerpo de un individuo, por una enfermedad propagada; el cuerpo político, por una intromisión violenta; o el cuerpo electrónico, por parte de un mensaje aberrante, lo que permanece invariado es el lugar en el cual se sitúa la amenaza, que es siempre el de la frontera entre el interior y el exterior, lo propio y lo extraño, lo individual y lo común. Alguien o algo penetra en un cuerpo -individual o colectivo- y lo altera, lo transforma, lo corrompe.

El término que mejor se presta a representar esta mecánica disolutiva -justamente por su polivalencia semántica, que lo ubica en el cruce entre los lenguajes de la biología, el derecho, la política y la comunicación- es 'contagio'. Lo que antes era sano, seguro, idéntico a sí mismo, ahora está expuesto a una contaminación que lo pone en riesgo de ser devastado (Esposito, 2005, p. 10).

El estado de excepción, la jungla, ya no está en la selva, sino en las calles asfaltadas y los edificios que quedan como testigos de la existencia de una civilización en vías de extinción. Una amenaza zombi representa un universo político decadente, sin capacidad de reaccionar y cuya única forma de sostenimiento es la implementación de mecanismos coercitivos de eliminación de los sospechosos. Los sobrevivientes desesperadamente intentaran reconstruir una nueva sociedad. De esta forma, el zombi constituye uno de los mejores escenarios para declarar el estado de excepción total, haciendo que los sujetos no pongan ningún reparo en la eliminación de extraños, dado que lo primordial es la protección de lo poco que queda de la sociedad 
En un apocalipsis zombi, la figura del antiguo derecho romano del homo sacer regresaría: "cualquiera puede matar sin por ello ser acusado de homicidio" y de esta forma todos nos convertimos en ser "cualsea”, “[...] que está aquí en cuestión no toma, desde luego, la singularidad en su indiferencia respecto a una propiedad común [...] sino sólo en un ser tal cual es" (Agamben, 2006, p. 11).

Demográficamente, al ser más zombis que humanos, las pocas autoridades decretarían un estado de excepción conducente a eliminar a cualquier sujeto amenazante, incluso, permitiendo el error:

La racionalidad del superviviente es un elemento clave para entender su diferencia legitimadora: tiene cerebro (e inclusive en la mayoría de los casos es su cerebro lo que lo pone en peligro). El zombi, por el contrario, anhela consumir ese cerebro-cuerpo mientras que el superviviente se valdrá de su cerebro-mente para mantenerse vivo (hablamos aquí del zombi “canónico"). Podríamos decir incluso que la oposición isotópica fundamental se traduce también en la lucha entre el cuerpo (un exceso de tacto, un deseo de aprehensión desesperado, una voracidad insaciable, una contigüidad sostenida: todo cuerpo) y la mente (un deseo de no ser aprehendido, una estrategia de escape, una separación anhelada) (Platzeck, 2016, p.79).

Hoy, el concepto de estado de excepción ha cobrado un interés para los debates de las ciencias sociales, la llegada del Covid-19 ha puesto en escena la importancia del estado de excepción, que no se restringe a un grupo social determinado, sino que se ha instalado para gran parte de la humanidad. La imposición de la cuarentena nos ha convertido en potenciales agentes de trasmisión, es decir, todos somos sospechosos de ser portadores del virus. Asimismo, esta situación ha visibilizado el hecho de que "la propagación continua de la epidemia del coronavirus también ha desencadenado grandes epidemias de virus ideológicos que estaban latentes en nuestras sociedades: noticias falsas, teorías de conspiración paranoicas, explosiones de racismo" (Zikek, 2020, p. 21).

El Covid-19 nos ha traído una situación a la que nadie tenía miedo, solo existía en la ciencia ficción, sin embargo, esta se ha convertido en una guerra médica a la que no estamos preparados, por ello damos la bienvenida al estado de excepción, que vine disfrazado de un discurso de seguridad, dando vía libre para la vulneración de los derechos humanos. La mirada de culpabilidad en el otro al que se debe ajusticiar a cualquier precio, como el que no porta mascarilla, el que acude al supermercado, al analfabeto que apenas sabes leer, ellos, entre otros, son los culpables. Inclusive, "la conciencia crítica ante la vigilancia digital es en Asia prácticamente inexistente. Apenas se habla ya de protección de datos, incluso en Estados liberales como Japón y Corea. Nadie se enoja por el frenesí de las autoridades para recopilar datos” (Han, 2020, p. 99).

La prolongación de un estado de excepción no solo implicaría el fin de una cotidianidad reglada por los derechos, sino que en su lugar habría una imposición de la militarización como forma política.

\section{LA GEOPOLÍTICA CINEMATOGRÁFICA DEL ZOMBI}

Shawn McIntosh (2008) ha descrito que los zombis se han apoderado de las junglas, de los océanos, del espacio, de los videojuegos, aun de la informática. Hoy deambulan tranquilamente por las calles de cualquier metrópoli, colonizando casi todo nuestro accionar. Incluso los debates filosóficos, antropológicos y sociológicos han sido seducidos por esta figura. Los zombis se han convertido en íconos populares, perpetuándose en el imaginario social como la especie que sobrevive al final de los tiempos.

En los últimos años las industrias culturales, especialmente el cine, nos han bombardeado con estos seres, con respecto a esto Antonio Pantoja afirma:

La excepcionalidad que caracteriza los relatos de ficción sobre los muertos vivientes es que, a pesar de que estas historias reales y documentadas han determinado la creación de la figura del zombi, es solo en la pantalla donde el zombi se ha convertido en un protagonista real y, por tanto, más creíble (Pantoja, 2017, p. 31).

Las construcciones culturales no son rígidas ni estáticas, sino que conducen a una serie de imaginarios sociales definidos como simbolismos de ciertas situaciones históricas. Con la popularización cinematográfica de los zombis desde los años sesenta, los muertos vivientes se configuran como imaginarios sociales que 
han permitido crear, según Frederic Jameson (1989), un heterotópico de la ficción (normalidad/anomalía; amigo/enemigo) manifestándose en una serie de contradicciones no asumidas por los discursos con que se narran y construyen las experiencias históricas.

El terror generado por los zombis es debido a la fobia al contagio, a la pérdida de autonomía y, desde lo cultural, representan una especie de tabula rasa sobre las ansiedades sociales existentes. En su forma moderna, los zombis constituyen metáforas apocalípticas del fin de las sociedades, donde todos los postulados filosóficos de la modernidad como la democracia, las leyes y la razón se desvanecen a favor de la ley del más fuerte.

Los sobrevivientes de una guerra zombi son reducidos a grupos pequeños, refugiados en cualquier lugar que pueda brindar seguridad, por lo general, claustrofóbicos. Las películas sobre zombis presentan similitudes escenográficas: la desconfianza entre los humanos sobrevivientes, ciudades desoladas, donde únicamente deambulan los zombis y grupos delincuenciales violentos que se adueñan de todo lo posible.

Estas películas poseen una capacidad de impactó en la población, dado que vivimos en constantes amenazas biológicas, químicas o nucleares, propiciamos los escenarios donde los zombis nacen. Los estudios sobre la temática del cine zombi pueden tener lecturas desde aspectos culturales, políticos y psicológicos (Dendle, 2007; Bishop, 2010). Por ello, este tópico no se puede tomar como algo inocente o sin valor de reflexión, pues estudiarlo es adentrase en los miedos invisibles y colectivos más profundos que poseemos.

Las nuevas narrativas cinematográficas sobre zombis se encuentran marcadas por las historias de horrores sociales y científicos causados por los humanos, que funcionan como un espejo desde donde se proyecta los males que causamos. De ahí que estas historias marchan como un "barómetro de ansiedad cultural" (Dendle, 2007, p. 45).

Para autores como Brym (2008), Sutherland y Feltey $(2012$, 2014) el análisis cinematográfico de los zombis se puede sustentar en las siguientes preguntas: uno, ¿los textos de zombis refleja el contexto social?; dos, ¿las historias de zombis distorsionan la realidad social?; tres, ¿a qué grado estas historias sacan a la luz problemas sociales?; cuatro, ¿hasta qué punto las narraciones se conectan con la estructura social?

No todo sobre los zombis puede ser ubicado como algo negativo. En las producciones audiovisuales se puede observar que las barreras culturales y raciales suelen desvanecerse frente a esta amenaza. Sin embargo, detrás de esta situación se esconde ciertos patrones raciales históricos como el paternalismo blanco y la servidumbre negra, indígena, asiática por citar algunas referencias.

En el cine zombi existe una imaginación del desastre, según Sontag (1996), que pone en escena diversos miedos, traumas y angustias existentes en nuestro aparataje social. En este sentido, las narraciones de zombis se encajan en escenas devastadoras que conllevan al colapso social.

Las ciudades arrasadas por hordas de zombis funcionan como un ejercicio político para redefinir nuevos escenarios para la humanidad, lo cuales deben adaptarse a nuevas formas de vida, toda la infraestructura tecnológica, los servicios básicos han dejado de funcionar, lo que el ser humano ha construido se ha derrumbado. La guerra contra los zombis pone en debate diversas propuestas políticas y filosóficas como la autosuficiencia y tolerancia hacia el otro.

Estas ficciones ponen en relato el pánico a un derrumbe del sistema, pero a la vez algunas de ellas operan como verdaderos laboratorios imaginarios en torno a las formas de vida posibles en una situación de colapso: el Nueva York tomado por la hierba y los animales salvajes de Soy Leyenda, la Atlanta devastada pero reverdecida de The Walking Dead (Kirkman y Moore, 2004-2014) o incluso la Barcelona deshecha y recorrida por un ciervo en Los últimos días (Pastor y Pastor, 2013) son algunas de las imágenes más evocadoras y hermosas de las ficciones del colapso contemporáneas. Porque más allá de la destrucción, puede vislumbrarse en ellas la potencia de nuevas formas de vida (Peris, 2018, p. 9).

El cine sobre un apocalipsis zombi es una situación que obliga a repensar de forma radical el funcionamiento de las sociedades que, sin leyes y cohesión entre los sujetos, se enfrentan para sobrevivir, situación que pone en duda la validez de cualquier argumentación legal.

Podemos hablar, en ese sentido, de la producción de un "estado de excepción narrativo" que suspende en el ámbito de la ficción las leyes del derecho, la moral y la costumbre, obligando a los personajes -y a los lectores o espectadores- a replantearse 
categorías básicas de las relaciones de convivencia y a redefinir en un contexto de amenaza extrema y violencia generalizada las legitimidades sociales y las opciones morales posibles. Muchas de estas ficciones ponen en relato, de hecho, la necesidad de reconstruir y reinventar las formas comunitarias en un contexto de peligro exterior máximo y en las que las lógicas e instituciones que sostenían las formas anteriores de lo colectivo se han hecho trizas (Peris, 2018, p. 9).

Por más ágiles que hoy sean los zombis, alejados de sus lentos y torpes antepasados, aún conservan ciertos rasgos como la poca inteligencia, lo que coloca el sentido de multitud como su real peligro; la amenaza de avalancha, que sitúa al zombi en la colectividad, alejado de otros monstruos individuales como los vampiros y extraterrestres.

En las narrativas contemporáneas se ponen en debate el temor a la movilización de grandes masas debido a que son incontrolables, violentas y destructivas. En política se debe diferenciar entre pueblo y masas/ multitud. "El pueblo es uno. La multitud, en cambio, es plural. La multitud se compone de innumerables diferencias internas que nunca podrían reducirse a una unidad, ni a una identidad única [...]" (Hardt y Negri, 2004, p. 16).

El zombi contemporáneo representa el despojo corporal, una deshumanización espiritual y psíquica, convirtiendo a este ser en una denuncia hacia el abandono, en el que se encuentran millones de personas que han sido despojadas del sentido humano y reducidas a simples objetos, una versión de vidas desperdiciadas.

En las crisis económicas, lo primero que se mueven son las masas descontroladas que buscan alimentos, agua y protección, de ahí que los individuos en masas actúen como zombis "desorientados, confundidos, en estado permanente de shock y vaciados de cualquier capacidad de agencia, los excluidos del neoliberalismo son conceptualizados como meros espectros sin voluntad" (Peris, 2018, p. 10). El cuerpo zombi refleja el menosprecio hacia los otros, no solo en el ámbito racial, sino hacia los mendigos, los pobres, los drogadictos, los migrantes y los enfermos, hacia todo aquello que se ubica como ajeno al entorno económico capitalista. Una amenaza zombi es la metáfora sobre el riesgo de una descomposición social global.

Películas como Diary of the Dead (2007) de George A. Romero, describe esa aberración a lo extraño, no en vano en su introducción la voz en off empieza con un "todo esto lo empezó un grupo de inmigrantes ilegales, que por error fueron tomados por muertos”. Los migrantes, los pobres y los que no se adaptan al sistema capitalista son los zombis excluidos fuera de toda oportunidad de progreso, como hordas que inundan e infectan los Estados "perfectos", donde el capitalismo se ha consagrado como el modelo ideal de justicia y oportunidad. Los migrantes, pobres y los que no se adaptan al sistema capitalista destruyen este modelo "perfecto" y esto hay que impedirlo y la única forma es matándolos, no incluyéndolos en el sistema. Por ello, en palabras de Yvan Barel:

[...] el vacío social es lo que ocurre en ciertas partes del cuerpo social que, o bien no son reconocibles ni visibles para otras partes del cuerpo social [...] o bien son sentidas por ellas como una fuente indistinta y confusa de peligros y amenazas (Barel, 1982, p. 160).

La temática de un apocalipsis zombi refleja diversas situaciones culturales, políticas, económicas y científicas que, de alguna manera, (re) configuran el panorama contemporáneo, así tenemos la desconfianza a los gobiernos, a las corporaciones y al propio desarrollo de la ciencia y tecnología.

Las películas zombis representan una tanatopolítica, la imagen de monstruos recorriendo y devorando a cualquier persona, por eso representan la metáfora para describir al mundo contemporáneo. Este ser presenta la idea de un desmoronamiento de los Estados por medio de la invasión de seres repulsivos, que representa a los sujetos marginados por el mercado, aquellos peligrosos que pueden desequilibrar el sistema actual. De esta forma:

Toda sociedad, pero también todo individuo, están atravesados por dos segmentaridades a la vez: una molar y otra molecular. Si se distinguen entre sí es porque no tienen los mismos términos, ni las mismas relaciones, ni la misma naturaleza, ni el mismo tipo de multiplicidad. Y son inseparables porque coexisten, pasan la una a la otra [...]. En resumen, todo es política pero toda política es a la vez macropolítica y micropolítica (Deleuze y Guatarri, 2002, p. 218). 
Por ello, los sujetos marginados, al igual que los zombis, deben ser encerrados en "campos de concentración" para perpetuar al sistema capitalista consumista.

El zombi, a día de hoy, ya no es una metáfora de lo real. Ya no sirve para hablar de la realidad, pues es ésta la que quizás se ha convertido en una metáfora del zombi, cambiando drásticamente los papeles. La realidad se ha zombificado por completo. Zombi sive natura (Díaz y Meloni, 2016, p. 67).

El zombi no es fantasma o un alma perdida, tampoco un diablo que recorre las calles, es un humano animalizado y aquí radica su problema: es otro humano, un semejante a alguien que fue un ser vivo, que espera una segunda muerte o, mejor dicho, una muerte segura que le permita descansar en paz.

No obstante, el zombi también presenta la otra cara del capitalismo, aquella que muestra que solo sobrevive cooperando junto al otro en la defensa contra los muertos caminantes. "El zombi nos devuelve al grado cero de la Historia, al paleolítico, para comenzar de nuevo, unidos, y es que la pedagogía zombi es entera- mente rousseauniana" (Díaz y Meloni, 2016, p. 28).

Las historias de zombis brindan miradas críticas para pensar las diversas conflictividades existentes en el mundo global y, como lo sostiene Kyle Bishop (2010), el cine de zombis se ha convertido en uno de los mejores barómetros culturales de la era moderna. "El miedo al zombi es el miedo a la democracia, a la multitud, a la inmigración, a la pobreza, a la enfermedad, a lo que es preciso deshumanizar con la metáfora de la masazombi antropófaga" (Díaz y Meloni, 2016, p. 34).

\section{Fin}

Los zombis no solo representan a cuerpos descompuestos, sino al miedo al contagio de algún virus y a la vez expone un rechazo a cualquier persona que se presuma contagiada. No obstante, en este punto hay que recalcar que se conserva una mirada colonial de los infectados, así tenemos que los asiáticos, latinos y negros son potenciales víctimas de una zombificación social, de esta forma se justifica la aplicación de políticas de sometimiento en nombre de la libertad, la democracia y la supervivencia humana.

Por ello asistimos a un terror generalizado por parte de los grupos de poder a las revueltas o levantamientos populares que pueden desequilibrar el orden político y económico establecido, así, la figura del zombi representa la metáfora de aquellos que se levantan reclamando sus derechos sociales, culturales, políticos y económicos. El aplastamiento de estas revueltas significa el triunfó de las políticas y fuerzas represoras que con los discursos de paz y seguridad exterminan a los "despreciables" sociales. Configurándose un "estado de excepción" como lo ha propuesto Agamben. La idea de una invasión zombi no solo queda para los debates de ciencia ficción, en estos se concreta una lógica y justificación ética de la autodefensa, seguridad y legítimo accionar violento contra cualquier extraño.

Una de las características cinematográficas del zombi es su capacidad de adaptarse a diversas expresiones artísticas y sociales. Desde los esclavos negros de White Zombie (1932) y Revolt of the zombies (1936), pasando por los cuerpos de los muertos poseídos por los marcianos de Invisible Invaders (1959), From outher space (1958), hasta los zombis antropófagos de Romero.

El zombi es una entidad extraña, un ser que pasó de racional a irracional, su presencia perturba a la cotidianidad, por ello cada etapa del cine zombi hace que estos monstruos posean cualidades diferentes. Sin embargo, hay algo que tienen en común, el peligro para la humanidad de un exterminio total. Más allá de esta situación, el cine zombi representa "el vehículo perfecto para sintetizar las angustias sobre la pérdida de la individualidad, la subversión política y el lavado de cerebro" (Verevis, 2010, p. 19).

El cine zombi no solo funciona como una metáfora y crítica social, sino que tiene una función pedagógica, muestran los escenarios posibles en caso de una invasión de estos personajes, el temor generalizado, la desesperación y el desorden social acompaña a la lucha por la supervivencia, además denuncia a los gobiernos 
que usan esta "guerra" para anular los derechos civiles, al pasar del estado de emergencia a un estado de excepción, con el fin de controlar a la población.

Daniel Drezner (2011) describe que este cine recrea los mayores temores de la humanidad como la guerra global, el terrorismo, el poder de las corporaciones privadas, los desastres nucleares, químicos y biológicos, por ello, el éxito de este cine radica en la posibilidad de que en algún momento llegue una amenaza real. De ahí que las narrativas fílmicas "[...] se sustentan en un marco narrativo apocalíptico o postapocalíptico muy presente en las manifestaciones culturales de la sociedad actual [...] y que a su vez constituyen expresiones de una realidad cultural propia del cambio de siglo" (Nespereira, 2014, p. 194).

Más allá de los discursos cinematográficos, los zombis representan una amenaza en dos cuestiones: la primera sobre el fracaso de la ciencia moderna y, la segunda, una pérdida de crítica y reflexión que conduce a sociedad irreflexivas y consumistas. Hoy este cine se ubica, por lo menos, en tres esferas reflexivas: 1) la explotación del cuerpo humano como lugar de disputas ideológicas y científicas, 2) una crítica hacia las sociedades consumistas e individualistas y, por último, 3) los discursos sobre la seguridad global fundamentados en el miedo al contagio del virus.

Por más fantasiosas que pueda resultar pensar en una invasión zombi, el uso de esta figura en los debates de las ciencias sociales permite pensar en formas nuevas de gobierno, amparados en políticas basadas en el miedo al contagio y con ello la justificación y aceptación civil de un estado de excepción permanente.

\section{ReFERENCIAS}

Agamben, G. (2006). Homo Sacer. El poder soberano y la nuda vida. Valencia: Pre-Textos.

Añón, A. (2018). Aproximaciones a la metáfora zombi en el cine: de Halperin a Romero. En M. Miguel (Ed.), ¿Quées el cine? IX congreso internacional de análisis textual (pp. 295-306). España: Ediciones Universidad de Valladolid.

Barel, Y. (1982). La marginalité sociale. París: Presses Universitaires de France.

Beck, U. (2002). De la sociedad industrial a la sociedad del riesgo: cuestiones de supervivencia, estructura social e ilustración ecológica. En La sociedad del riesgo global (pp. 75-113). Madrid: Siglo XXI.

Bishop, K. (2010). Dead Man Still Walking: Explaining the Zombie Renaissan-ce. Journal of Popular Film and Television, 37(1), 16-25.

Boluk, S. y Lenz, W. (2011). Introduction: Generation Z, the age of apocalypse. En S. Boluk y W. Lenz (Eds.), Generation zombie. Essays on the living dead in the modern culture (pp. 91-99). North Carolina: McFarland \& Company.

Braidotti, R. (2009). Lo Posthumano. Barcelona: Gedisa.

Calabrese, O. (1989). La era neobarroca. Madrid: Cátedra.

Castro, S. (2007). Michel Foucault y la colonialidad del poder. Revista Tabula Rasa, 6, 153-172.

Chalmers, D. (1999). La mente consciente. Barcelona: Editorial Editorial Gedisa.

Cohen, J. (1996). Monster Theory. Estados Unidos: University of Minnesota Press.

Coulombe, M. (2012). Petite philosophie du zombie. Paris: Presses Universitaires de France.

Deleuze, G. y Guattari, F. (2002). Micropolítica y segmentaridad. En Mil Mesetas: Capitalismo y esquizofrenia (pp. 213-238). Valencia: Pre-textos.

Del Olmo, A. (2012). El eterno retorno del no-muerto como arquetipo filmico: Una aproximación a la figura del zombi en la cultura popular contemporánea (Tesis de doctorado). Repositorio Institucional. Universitat Ramon Llull, Barcelona, España.

Dendle, P. (2007). Monsters and the Monstrous. New York: Rodopi.

Díaz, J. y Meloni, C. (2016). Abecedario zombi. Madrid: El Salmón Contracorriente.

Esposito, R. (2005). Inmunnitas. Protección y negación de la vida. Buenos Aires: Amorrortu Editores.

Fernández, J. (2011). Filosofía zombi. Barcelona: Anagrama. 
Mag. Xavier Brito Alvarado, et al. La geopolítica cinematográfica de los zombis: notas Para el deb...

Han, B. (2020). La emergencia viral y el mundo de mañana. En P. Amadeo (Ed.), Sopa de Wuhan. Pensamiento contemporáneo en tiempos de pandemia (pp. 97-112). Buenos Aires: Editorial ASPO (Aislamiento Social Preventivo y Obligatorio).

Hardt, M. y Negri, A. (2004). Multitud. Barcelona: Debosillo.

Mcintosh, S. y Leverette, M. (2008). Zombie Culture: Autopsies of the Living Dead. Toronto: The Scarecrow Press.

Moraña, M. (2017). El monstruo como máquina de guerra. Iberoamericana Madrid: Editorial Vervuert.

Nespereira, J. (2014). Los discursos de la pandemia. Nuevas estrategias de comunicación del riesgo en un nuevo contexto sociocultural. Revista de Estudios Culturales de la Universitat Jaume I, 13, 185-199.

Pantoja, A. (2017). Tiempo de zombis: la realidad de los muertos vivientes en la ficción cinematográfica. En M. Urraco, J. García y M. Baelo (Eds.), Mundos Z. Sociologías del género zombi (pp. 31-51). Madrid: Los libros de la Catarata.

Peris, J. (2018). Ficciones inmunitarias. Sobre la lógica de la inmunidad en la cultura contemporánea. Papeles del CEIC, $1,1-32$.

Platzeck, J. (2016). El monstruo y el poder: un diálogo entre biopolítica y zombies. Revista Representaciones, 12(1), 77-94.

Sánchez, R. (2013). Muertos, infectados y poseídos: el zombi en el cine español contemporáneo. Revista de Estudios Hispánicos Pasavento, 1, 11-34.

Sontag, S. (1996). Contra la interpretación. Madrid: Alfaguara.

Urraco, M., García, J. y Baelo, M. (Eds.). (2017). Mundos Z. Sociologías del género zombi. Madrid: Los libros de la Catarata.

Verevis, C. (2010). Redefining the Sequel. The Case of the (Living) Dead. En C. Jess-Cooke y C. Verevis (Eds.), Second Takes: Critical Approaches to the Film Sequel (pp. 11-30). Albany, Sontag: SUNY Press.

ŽiŽek, S. (2020). El coronavirus es un golpe al capitalismo a lo Kill Bill. En P. Amadeo (Ed.), Sopa de Wuhan. Pensamiento contemporáneo en tiempos de pandemia (pp. 21-29). Buenos Aires: Editorial ASPO (Aislamiento Social Preventivo y Obligatorio).

\section{BY-NC-ND}

